\title{
Coronavirus and a greener future
}

\author{
Stephen Hancocks OBE \\ Editor-in-Chief
}

The BDJ Upfront section includes editorials, letters, news, book reviews and interviews. Please direct your correspondence to the News Editor,

Kate Quinlan at k.quinlan@nature.com. Press releases or articles may be edited, and should include a colour photograph if possible.

I usually try to focus on one topic for editorials but with the unprecedented current circumstances surrounding the coronavirus and some positive and exciting news on the journal I am breaking the rule.

Firstly 'the' virus. We have been receiving a stream of emails and letters to the editor with suggestions, urges to publish guidance and people's thoughts and even some 'research' papers (!) on the subject. Our approach to the virus in relation to dentistry is guided by two factors; time to publication and international readership. The $B D J$ is relatively unusual in that it is published twice a month. However, even this means that for any content from the moment of acceptance to the appearance in the publication there is a delay of two to three weeks. With a fast-moving situation as with the coronavirus this means that any information we publish risks being seriously out of date and possibly contradictory within this timeframe. Other agencies and forms of media are therefore far more appropriate and fit for purpose for the dissemination of up to date information. Our advice therefore is for readers to refer to the websites, and any trusted social media sources that they select, of their national or regional dental associations, governments, health departments or organisations, trade bodies and so forth for pertinent and timely guidance. This applies variously to roles we have as clinicians, healthcare providers, team leaders, employers and small business owners.

This point also reflects our now very wide international readership. While the $B D J$ is the journal of the British Dental Association, and as such we direct British readers and BDA members to the BDA website for the latest and most comprehensive information on the impact of the pandemic on their daily work (www.bda.org/advice/Coronavirus), we would similarly direct readers from other countries and jurisdictions to their dental associations. Advice in one place may differ materially and substantially from that in another depending on a wide range of factors. Ultimately it is our opinion that the 'local' guidance must take precedence. In due course, as the world heals, I am sure we will publish content on lessons learnt and procedures to take forward as well as papers and articles on a variety of circumstances and oral health care impacts that this extraordinary set of circumstances has created. If you have content now that you feel falls into this definition then please do not feel restrained in submitting it to us but otherwise, in the meantime, we will continue as usual to offer our valued spread of information, clinical and research topics. Also, our publishing partner Springer Nature is committed to supporting the global response to emerging shopping bags we have received an increasing number of requests from readers and BDA members to review this.

The principle alternatives to plastic for this purpose are paper and biodegradable vegetable starch. A range of properties have to be considered including material availability, strength and sustainability as well as suitability for production processes. After considerable research we have been advised that the use of sustainably-sourced paper is current best practice. We are therefore delighted to announce this change, meaning that the entire publication and delivery envelope are recyclable, removing over 400k pieces of plastic from the waste stream per year. There will be one, occasional, exception to this, for example

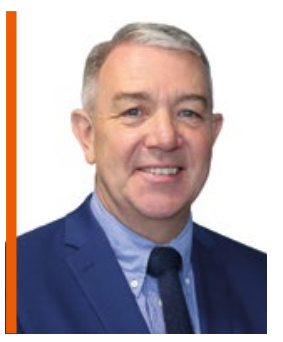

\section{'It is our opinion that the "local" guidance must take precedence'}

outbreaks by enabling fast and direct access to the latest available research, evidence, and data (www.springernature.com/gp/researchers/ campaigns/coronavirus).

So to my second topic. Readers accessing this online will probably not notice the main change that has taken place with the publication of this issue. Readers who have received this as a print copy and are digesting these words will have had to open the paper envelope in which it was delivered. With this issue we have changed from the plastic poly-wrapping which has been used for longer than anyone can actually pinpoint but in any event from the time at which 'plastic' was deemed very modern and the 'thing to use', to paper. Although the plastic was changed some while ago to a recyclable variant similar to that utilised for supermarket if, and as and when, an oral health company wishes to enclose a toothpaste sample for the benefit of readers, we will have to revert to recyclable plastic for reasons of strength and robustness through the postal system.

Our primary intention in bringing in this change is to acknowledge the part we can all play in moving towards a greener future and helping to protect the resources of the planet on which we all rely. It also demonstrates how we are willing to consider, investigate and react to concerns expressed to us, and is very much in the same spirit in which we have already published papers on green dentistry.

In closing, my sincerest wishes to all readers for good health for yourselves, team members and loved ones in these difficult times.

https://doi.org/ 10.1038/s41415-020-1432-y 